\title{
A linguagem politicamente correta e a análise do discurso
}

Sírio Possenti

IEL / UNICAMP

\section{Abstract}

The main argument of the present paper is that certain linguistic facts - which are central in the dispute for a politically correct use of language - are of paramount importance for discourse analysis, especially in the French tradition. In this theory, language functioning and meaning are explained in terms of historical postulates. Yet, such facts are frequently disputed by speakers, and this has the consequence of making explicit the fight for words and their senses. The widest known cases are those which encompass racist (e. g. black vs. afrobrazilian or afro-american) or sexist (e. g. sissy vs. homosexual) language. 
"A situação tá preta, e vai ficar mais feia ainda lá pros lados do Fluminense" (de um comentarista esportivo)

1

.A expressão "politicamente correto" (ou incorreto) aplica-se hoje não apenas à linguagem, embora esta seja a candidata mais plo, em um recente dia dos namorados, um jornal afirma que "casais entram na era do politicamente correto, são fiéis, trocam anéis e fazem sexo responsável". Uma revista de variedades informou há pouco tempo que as redes inglesas de TV BBC e Channel 4 tiraram do ar algumas mímicas (p. ex., o dedo em forma de gancho que queria dizer 'judeu', puxar os cantos dos olhos para representar um chinês) que eram utilizadas em programas para surdos-mudos, por julgá-las politicamente incorretas.

Para alguns, como o pensador francês C. Lefort, trata-se de um movimento muito localizado e quase idiossincrático: "é um fenômeno americano, anglo-saxônico, que é insuportável, mas que é interessante na medida em que parece traduzir algo de muito antigo em uma certa tradição de seita nos Estados Unidos. Como se tudo precisasse passar por uma regra para poder existir" (Folha de S. Paulo, 20.03.94). Para outros, o fenômeno até pode ser tipicamente americano, mas isso não implica necessariamente a conotação de seita que Lefort lhe atribui. $O$ filósofo Renato Janine Ribeiro, por exemplo, assinala que o movimento pode até apresentar problemas, mas é resultado da organização das minorias, e que, se é fraco no Brasil, isso se deve mais a suas virtudes que a seus defeitos. Sua pouca força resultaria do fato de que aqui as minorias são pouco organizadas (Ribeiro 1992).

2.Os estudantes de uma universidade devem ser selecionados 
apenas através de provas, idênticas para todos os candidatos, ou as vagas devem ser distribuídas, por quotas proporcionais, entre as diversas etnias e opçð̃es sexuais? Ainda é razoável que em inglês as mulheres sejam designadas pela palavra "woman" e as pessoas pela palavra "person", ou a presença nelas de segmentos como "man" e "son" exigiria que fossem abandonadas e substituídas por outras, que não contenham segmentos semelhantes e que não produzam certos efeitos de sentido? A história da humanidade pode ser chamada de "history"? Ou então ela seria uma história inevitavelmente marcada pelo ponto de vista masculino?

Tais questões estão sendo propostas em conjunto, e ainda acompanhadas de outras, na defesa de um comportamento, inclusive lingüístico, que seja politicamente correto. $O$ movimento inclui em especial o combate ao racismo e ao machismo, à pretensa superioridade do homem branco ocidental e à sua cultura, pretensamente racional. Estas são, digamos, as grandes questões. Mas o movimento vai além, tentando tornar não marcado o vocabulário (e o comportamento) relativo a qualquer grupo discriminado, dos velhos ao canhotos, dos carecas aos baixinhos, dos fanhos aos gagos. As formas lingüísticas estão entre os elementos de combate que mais se destacam, na medida em que se acredita (com muita justiça, em princípio) que reproduzem uma ideologia que segrega em termos de classe, sexo, raça e outras características físicas e sociais objeto de discriminação, o que equivale a afirmar que há formas linguísticas que veiculam sentidos que evidentemente discriminam (preto, gata, bicha), ao lado de outros que também discriminem, embora menos claramente (mulato, denegrir, judiar, anchorman, history etc). A análise desses fatos, na medida em que são confrontados com os de uma linguagem que, ao contrário dessa, seria politicamente correta, permite discutir o que pode significar, em especial para teorias do sentido, esta atividade "epilingǘrstica" que classifica expressões em politicamente corretas ou incorretas e que transforma esta qualificação em objeto de militância.

Para alguns, este movimento é basicamente ùm efeito do relativismo e da crise da racionalidade (ver Berman, 1992, especial- 
mente "Introduction", e Hughes, 1993), em especial quando atacam valores ligados à cultura clássica. Para outros, é um dos resultados da organização das minorias. Seja como for, trata-se de um movimento confuso, com altos e baixos, que comporta algumas teses relevantes, outras extremamente discutíveis e ainda outras francamente risíveis. $\mathrm{O}$ que quer que se diga em relação aos efeitos políticos, no entanto, estamos diante de um movimento que já produziu fatos discursivos que não podem deixar de ser analisados, independentemente da sua durabilidade histórica e da solidez das teses que os justificam.

Para alguns, este movimento corre o risco de transformar-se numa forma de censura. Um dos efeitos seria o cerceamento da liberdade de expressão. Diversos campos de manifestação cultural certamente tenderiam a ser afetados por um comportamento politicamente correto. Durante as filmagens de Basic Instinct, por exemplo, houve violentas manifestaçð̃es de homossexuais, motivadas pelo fato de que no filme a personagem suspeita de diversos assassinatos era uma lésbica. Os militantes temiam que o filme estigmatizasse esse grupo. Em entrevistas, o diretor reagiu, dizendo que é impossível ser politicamente correto ao fazer um drama. Jornais informam que um romancista japonês anuncia que vai parar de escrever porque a proibição atinge cada vez mais palavras. A razão imediata é um livro no qual, segundo uma associação de epilépticos, o autor definiu mal a doença e cometeu assim um atentado a seus direitos. Recentemente, os autores de uma telenovela brasileira foram atacados por vários grupos atuantes em movimentos negros, alguns alegando que haveria divulgação de idéias racistas na novela, em decorrência de certas expressões muito marcadas utilizadas por uma das personagens; outros reclamavam basicamente do comportamento passivo da personagem negra que fora agredida, alegando que esta postura atribuída a um negro é inadequada e prejudicial.

Outros imaginam que, com a campanha, as línguas se empobreceriam. De fato, há muitas palavras que podem ser analisadas como politicamente incorretas. Se fossem proibidas (como a Namíbia proibiu oficialmente palavras que conotavam submissão dos nativos aos brancos, ou eram marcas de uma relação colonialista), itens lexicais 
seriam perdidos e, com isso, documentos da história da língua (e da cultura). Veja-se como um intelectual brasileiro se posiciona diante do fato: afirma que "com argumentos assim, o vocabulário vai sofrer um expurgo de todo tamanho. Muitas palavras vão ser cassadas". 0 cronista argumenta que "rubro-negro" pode vir a ser considerada uma expressão ofensiva a índios e negros, que a China poderia ofender-se com nossa expressão "febre amarela", o Japão com a outra, "perigo amarelo", que a China brigaria com os franceses por causa da expressão "chinoiserie", que a França reclamaria do fato de que se fala "sair à francesa", os judeus, por causa de "judiar", os negros, ainda, por causa de "denegrir" etc. Sem falar da informação que motiva a crônica, segundo a qual alguns advogados da causa dos indígenas americanos querem mudar o nome de um time de futebol de Washington, os Redskins - Peles Vermelhas (Resende, 1992).

3.Este trabalho basicamente comenta a relevância, em especial para a Análise do Discurso (doravante $\mathrm{AD}$ ) de algumas formas lingüisticas cujo sentido conota desvalorização de indivíduos ou grupos, levando em consideração basicamente alguns casos nos quais certas palavras estiveram em disputa, já que esses fatos revelam um determinado jogo de forças e explicitam alguns dos argumentos utilizados. A ênfase em tais fatos (ou tipos de fatos) se justifica pela relevância que a $\mathrm{AD}$ reserva às condiçð̃es extralingüísticas na produção dos efeitos que os enunciados (ou as palavras) produzem por ocorrer nos discursos em que ocorrem. Embora os dados que tenho não sejam muito numerosos, espero que sejam suficientemente significativos. $O$ trabalho se situa no encontro de duas pesquisas pessoais em curso: uma sobre o humor (que é muitas vezes politicamente incorreto) e outra sobre algumas questões teóricas no interior da $\mathrm{AD}$ (em especial a questão da heterogeneidade da linguagem e a das diversas posições do sujeito).

Analisar dados como esses é, em mais de um sentido, analisar o funcionamento ideológico da linguagem. Pode parecer que a relevância da discussão seja prioritariamente política mas, como disse acima, o que se passa fora da língua é freqüentemente relevante para 
a própria linguagem. Por isso, a discussão não é apenas política, embora este seja certamente um aspecto importante. Para os interessados em discutir o velho e insolúvel problema da relação entre som e sentido, por exemplo, trata-se de um fenômeno que exibe à luz do dia alguns dos seus aspectos mais cruciais: a) que a significação depende dos discursos em que as palavras e enunciados ocorrem; b) que a relação entre som e sentido (só) é explicável historicamente; c) que é ela em parte que faz com que textos sejam considerados racistas, machistas etc; d) que há alguma relação entre o sujeito do discurso e o discurso, mas, no fim das contas, o sentido independe (das intenções) dos sujeitos que produzem os enunciados. Suponho que, para os que aceitam que o sentido é convencional - no fundo, a maioria absoluta dos lingüistas e filósofos da linguagem -, os fatos aqui comentados servem como razóes para o abandono de tal hipótese.

De fato, o movimento em defesa de um uso politicamente correto da linguagem fornece evidências vivas em favor da teoria da $\mathrm{AD}$ e, em especial, da afirmação de Bakhtin segundo a qual o signo não reflete, mas refrata a realidade, tornando-se, por consequiência, uma arena da luta de classes (Bakhtin/Voloshinov (1929:46). Assim, suas implicações para as teorias do sentido são óbvias, já que o movimento mostra de forma indiscutível como se dá a disputa pelo sentido de certas palavras, pois o movimento consiște em grande parte nessa luta ("discriminatory comments on the form of name calling, racial slurs, or jokes", segundo a revista Newsweek de 24 de dezembro de 1990) e na denúncia dos efeitos de sentido que o uso de certas formas implica. Tais palavras, cujo uso e cujo sentido são objeto de disputa, permitem, pois, assistir ao vivo a várias micro-histórias semânticas de alto valor epistemológico, já que exibem claramente o processo de criação de certos efeitos de sentido (Para um semanticista, ou para um analista do discurso, esses dados têm uma relevância semelhante à que têm dados de aquisição de linguagem, de pidgins ou de crioulos, exceto talvez pelo fato de que o movimento por uma linguagem politicamente correta produz dados com grau de "seriedade" variado. Mas, de qualquer forma, ilustram abertamente um processo relevante para as línguas). Além disso, e de forma talvez mais interessante, os 
dados manifestam discordâncias mesmo entre falantes que aparentemente deveriam estar do mesmo lado (se só houvesse dois lados), sobre quais são as palavras mais adequadas e quais são seus reais sentidos.

Portanto, os elementos discursivos mais críticos da chamada linguagem politicamente (in)correta são dados empíricos de extrema relevância para sustentar teses centrais da $\mathrm{AD}$. Por um lado, a análise de certos itens lexicais (negro vs. afro-brasileiro (ou americano), homossexual vs. bicha, moça vs. gata, por exemplo) mostra a clara relação desses itens com as formaçб̃es discursivas históricas nas quais tais itens ganham os sentidos que ganham. Como os sentidos não são os mesmos para os diversos falantes situados em lugares sociais diferentes, teses clássicas da $\mathrm{AD}$ ficam bastante confirmadas por esses dados, e de modo muito claro. Por outro lado, também os locutores que produzem tais discursos acabam por ser classificados, por exemplo, como racistas, machistas (genericamente, preconceituosos), com base em sua prática discursiva, ou pelo menos também através dela, mesmo que não tenham intenção de produzir os efeitos que produzem falando, ou, ainda mais, mesmo que não se dêem conta de que seus discursos, por incluírem determinados termos marcados, produzem tais efeitos. Além disso, há outro aspecto relevante: alguns falantes manifestam algum grau de consciência e outros, não, da carga negativa ou positiva de certos termos; ou, alternativamente, alguns falantes se dão conta da carga negativa de certos termos apenas quando aplicados "inadequadamente" (ver Possenti, 1994, a propósito da palavra "caipira").

É relativamente óbvio que tais dados têm um relevo especial em relação àquelas teses centrais da $\mathrm{AD}$. Nada melhor para verificar uma concepção de discurso como uma prática social e histórica do que ver e viver disputas de sentidos, materializada na luta pelo emprego de certas palavras e na luta para evitar o emprego de outras. O que é ainda mais relevante nesses dados é que não só eles aparecem nos discursos, mas são abertamente discutidos e avaliados, às vezes de forma bastante interessante, embora às vezes também de forma grosseira. Essas análises, no entanto, além de serem mais ou menos feli- 
zes do ponto de vista técnico, são ainda mais relevantes pelo fato de que revelam as forças sociais que lutam pela legitimidade de alguns discursos e pela ilegitimidade de outros. É um tipo de dado relativamente raro, que o pesquisador não pode desprezar.

A recente discussão sobre o emprego da palavra "mulato" por parte de um candidato a presidente, como resposta a uma tentativa de um adversário de caracterizá-lo como sendo de elite, e, em particular, as reações que o emprego de tal palavra provocou por parte de militantes de movimentos organizados e de outros cidadãos que decidiram intervir no debate, ilustram de forma clara o tipo de material que interessa de forma relevante para a $\mathrm{AD}$. Ao mesmo tempo que a disputa fornece dados ao analista, o próprio fato de que ela se dê através da imprensa ajuda a esclarecer sua relevância, já que a discussão caracteriza-se como um caso em que forças sociais que agem com e sobre a linguagem explicitam suas posiçőes, apelam para argumentos de várias ordens, alguns supostamente científicos, tentando produzir efeitos sobre a linguagem de forma mais ou menos consciente e organizada - ao contrário do movimento em geral imperceptível das forças envolvidas classicamente nos processos de variação e de mudança lingüísticas, que são perceptíveis, quando o são, para especialistas munidos de instrumentos de observação não disponíveis para falantes comuns, embora as forças sejam fundamentalmente as mesmas.

Vejam-se alguns exemplos de intervenção no aludido episódio: a) Uma reportagem registra a seguinte afirmação de um militante negro: "Só se ele é filho de mula. Mulatinho é cruzamento com mula, não com negro". b) Cartas de leitores apresentam análises do fato, afirmando, por exemplo, que Fernando Henrique deveria saber que a palavra "mulato" tem origem pejorativa e que certos movimentos negros lutam contra sua utilização. Outra carta baseia sua argumentação na análise etimológica corrente, afirmando que, além do caráter pejorativo do termo "mulatinho" para se referir ao negro, o fato se agrava pelo fato de a palavra "mulato" originar-se de "mula". Outra carta de leitor assinala, no entanto, que a palavra "mulato" não deriva de "mula", mas de um vocábulo árabe (aprox. [mohalát]) que signifi- 
ca 'mestiço'. A idéia que subjaz a esta discussão é que, se uma hipótese etimológica for verdadeira, a palavra veicula racismo; mas, se verdadeira for a outra, também etimológica, a palavra "mulato" se tornaria limpa, não veicularia racismo. $O$ colunista Jânio de Freitas entra na questão e faz uma análise que um lingüista poderia assinar: "... atribuir a todo uso da palavra mulato um sentido ofensivo ou discriminatório, como tantos estão fazendo, é negar a natureza dinâmica da linguagem, com sua permanente modificação de formas e sentidos. Mesmo que a procedência etimológica de mulato tenha a incomprovada relação com mula, seu sentido não guarda sequer vestígio desta suposta origem" (Folha de S. Paulo, 08.02.94).

A atividade do movimento em favor de comportamentos politicamente corretos, além de combater o uso de termos marcados negativamente, caracteriza-se também por propor a substituição de tais termos por outros, que seriam "neutros" ou "objetivos". Assim, os membros de uma certa comunidade étnica não devem ser chamados de "negros", mas de "afro-americanos" (ou de "afro-brasileiros"), ou, como se verá adiante, até mesmo de "afrodescendentes". A hipótese do movimento, no caso, parece ser a de que a conotação (ver KerbrachOrecchioni, 1977) negativa está ligada à própria palavra. A tese da AD seria, ao contrário, a de que a palavra produz os efeitos de sentido que produz em decorrência do discurso a que pertence tipicamente (um discurso racista, por exemplo). Tal discurso só ocorre se a sociedade for de alguma forma racista. Vale dizer, se houver suporte (para a AD, "se houver condições de produção") sociológico e histórico na formação social para que haja uma ideologia racista que se materialize num discurso que contenha marcas características dessa ideologia. Esta dupla posição em relação ao peso das palavras - peso que seria intrinsecamente seu, segundo uma hipotese, ou que derivaria dos discursos nos quais são enunciadas, segundo outra - mostra claramente a relevância do problema em questão e a diferença entre as hipóteses que tentam explicar o que ocorre no domínio do sentido.

Os textos que contêm elementos relevantes, e dos quais pretendo esboçar uma análise, mostram claramente que há grupos organizados em torno dos sentidos das palavras e que lutam para que alguns sen- 
tidos sejam vitoriosos e outros sejam eliminados. Segundo esta perspectiva, considero realista pensar que se trata de exemplos vivos de que a significação só pode ser explicada através de uma história entendida como marcada pela luta de classes, luta que se dá tanto em torno de bens materiais quanto em torno de bens simbólicos (Bourdieu, 1983). É fato que a luta se dá também, ou prioritariamente, contra termos que conotam negativamente em relação a grupos que, em sua maioria, não atendem aos critérios de classe segundo o marxismo clássico. Grupos que lutam por direitos de igualdade para quem pertence a determinado sexo ou raça, por exemplo, ao contrário de se constituírem em contra-exemplos aos princípios históricos acima expostos, são exemplos de novas formas de lutas; estudiosos como Anderson (1983) defenderam este ponto de vista a propósito de lutas como as que se dão pelas causas feministas, ou pelas causas das raças discriminadas, ou em favor dos direitos dos que fazem opções sexuais que são objeto de preconceito.

0 interesse em discutir tais casos é evidente para discursos progressistas, mas quereria argumentar que o interesse é ainda maior para as teorias do sentido, isto é, para a lingǘrstica. Do ponto de vista mais estrito do estudo da relação da forma e do sentido, trata-se de um fenômeno que exibe à luz do dia um dos aspectos mais cruciais do problema da significação: a saber, que a significação apresenta-se como tendo a seguinte dupla face: ao mesmo tempo, ela depende dos discursos nos quais aparecem os meios de expressão e em grande parte é ela que os faz serem os discursos que são.

4. Em Possenti (1994) analiso alguns dados colhidos em jornais brasileiros. Retomo, aqui, um dos dados, que me parece o mais significativo de todos. Para que ele se torne inteligível, é necessário explicitar minimamente suas condiçóes de produção.

Em lo de maio de 1992, ao noticiar uma nova versão de seu Manual de Redação, o jornal Folha de S. Paulo deu particular destaque ao fato de que estava atento à linguagem politicamente incorreta. E transcreveu exemplos do que propunha como norma aos jornalistas da casa. Por exemplo: evitar termos como "preto, crioulo, escurinho, 
alemão, moreno, de cor"; utilizar "negro"; mas também não utilizar expressóes como "afro-brasileiro, cidadão de tipo negróide". $O$ jornal não explicita seus critérios, mas isso não é necessário. É evidente para quem fala português no Brasil, isto é, para quem está mergulhado nessa cultura, que a primeira das listas contém palavras cujo efeito é claramente discriminatório. A última lista, por sua vez, revela que provavelmente a direção do jornal se tenha dado conta de que a utilização de termos escolhidos com demasiado cuidado denunciaria, exatamente pelo cuidado excessivo, atitudes racistas. Assim como a denegação acaba por afirmar, escolhas não usuais pareceriam sintoma do preconceito. A recomendação para usar "negro" é provavelmente mais corajosa do que isenta, porque nada garante que, uniformemente, esta palavra seja considerada neutra do ponto de vista dos discursos racista e anti-racista.

Outro exemplo destacado pela mesma edição daquele jornal: evitar "bicha, veado, fresco, boneca, traveco, sapatão, ela calça 42"; utilizar "homossexual, travesti, lésbica"; não utilizar "gay (significa feliz), alfenado, safista". Ora, foi em reação a esta sugestão do Manual que o jornal recebeu e publicou a seguinte carta:

"Gostaria de apontar uma sutil incorreção no 'Novo Manual de Redação' da Folha. Ao referir aos termos sinônimos de homossexualidade, sugere evitar os chulos 'bicha, veado, boneca, traveco, sapatão', substituindo-os por 'homossexual, travesti e lésbica', desaconselhando o uso dos termos 'gay (que significa feliz), alfenado e safista'. Primeiro uma correção: o étimo gay provém da língua catalãprovençal, redundando no português gai, tanto quanto no inglês significando alegre (e não 'feliz'), e desde o século 13, segundo pesquisas do sr. John Boswell, da Universidade da Califórnia, é utilizado exatamente no mesmo sentido contemporâneo, como sinônimo de homossexual. Segundo reparo: o termo homossexual foi usado pela primeira vez em 1869, cunhado pelo escritor uranista Benkert, sendo imediatamente apropriado pelo saber médico como 
designativo 'científico' em substituição ao antigo 'sodomita'. Há mais de duas décadas, no mundo inteiro, os homófilos adotaram o termo gay para se autoidentificar, preferindo-o ao ascético 'homossexual', que consideram uma imposição da medicina. Se a Folha privilegia o termo negro, em lugar de crioulo, preto etc - adotando exatamente o designativo preferido dos afrodescendentes brasileiros -, que respeite igualmente a preferência das lésbicas, travestis e homossexuais de nosso país, que há mais de uma década se autoidentificam como gays". (Luiz Mott, presidente do grupo Gay da Bahia - Salvador, BA)

Esta carta traz interessantes ilustrações para as teses da Análise do Discurso sobre o sentido. Inclusive pelos equívocos implícitos. A carta relaciona explicitamente certas palavras e certos discursos. Por exemplo, 'homossexual' pertenceria ao discurso médico e a um genérico discurso ascético. Declara, além disso, que os homossexuais aceitam ser chamados de "gays". Não rejeita o termo "homossexual", mas discorda que o termo "gay" seja impróprio; defende, portanto, seu uso, contra os preceitos do jornal, o que implica avaliar de maneira diversa seus efeitos de sentido. Essas teses ficam explicitadas. Mas o autor refere-se aos homossexuais também pela palavra "homófilos". De modo análogo, ao mesmo tempo que apóia o jornal por escolher o termo "negro", refere-se ao grupo assim designado com a palavra "afrodescendentes"! O que estes dois fatos implicam é que haveria palavras, como "afrodescendentes" e "homófilos", acima de qualquer suspeita. Seriam palavras que simplesmente descrevem - etimologicamente? - origens étnicas e opçőes sexuais! Em "afrodescendente" não há nada que signifique ou conote cor. Em "homófilo" não há nada que signifique ou conote sexo. Como cor e sexo são as razóes da discriminação, tais palavras fariam com que os discursos em que aparecessem passassem a ser politicamente neutros. Como se houvesse palavras que apenas refletissem, sem refratar, a realidade (Note-se que as avaliaçőes da Folha e de Luiz Mott não coincidem, embora ambos queiram ser politicamente corretos. $O$ 
que mostra claramente que há variados discursos, o que torna complexa - e necessariamente discursiva - a questão semântica).

O exemplo seguinte, semelhante ao anterior, exceto pelo fato de a incorreção política, neste caso, ser menos clara, é menos óbvio para os propósitos deste trabalho, mas, por outro lado, talvez seja mais interessante para discutir os limites do movimento. Veja-se a carta abaixo, publicada na revista ISTOÉ 1208 , de 25.11.92, e a resposta da revista:

Sr. Diretor:

Sou assiduo leitor desta revista, sempre a tive como grande veículo de comunicação sério e de grande responsabilidade. Porém, na edição 1206, assunto religião, onde vocês comentam a grande importância de Galileu Galilei na história, há um trecho onde lê-se "um dos periodos mais negro (sic!) da história". Devido a essa frase, venho expor meu repúdio e questionamento. No momento em que isso é referido, não há afirmação de que negro é sinônimo de desgraça histórica? (Robson Carlos Almeida, Salvador - BA)

ISTOÉ explica: No sentido em que a palavra negro foi usada, ela é tão ofensiva quanto dizer que houve um golpe branco em um determinado pais, por exemplo.

Lendo essa carta e a resposta da revista, um fato fica relativamente nítido: a palavra "negro", num certo enunciado, não tem os mesmos efeitos de sentido que tem para para um falante e para outro. A questão relativa aos eventuais preconceitos que a palavra "negro" e outras palavras a ela associadas ("denegrir", p. ex.) veiculam não é certamente simples. No entanto, mesmo uma análise breve, um pouco mais cuidadosa, pode mostrar em que sentido a resposta da revista confirma ou não o preconceito veiculado pela palavra "negro" do texto criticado pela carta.

Pensemos por um momento nos discursos políticos relativos às revoluçð̃es: num deles, um discurso que materializasse uma ideolo- 
gia que conferisse à ordem jurídica o papel de maior destaque numa determinada formação social, uma revolução branca é obviamente um fato negativo, se comparada com uma situação de legalidade. Ora, essa expressão, tal como aparece na resposta da revista - que, por sua vez, a retoma do uso e com o sentido corrente -, acaba significando, para o que é aqui relevante, que a revolução năo foi sangrenta, o que não deixa de ser uma avaliação positiva, dadas as circunstâncias (é como se se dissesse: já que houve uma revolução, pelo menos foi branca). Mas isso não esgota a análise. A principal questão é: ser branca opøe-se a quê? Se houvesse sangue, dir-se-ia que foi um período negro? Se sim, então "revolução branca" pode evocar racismo. A revista, neste caso, confirmaria o ponto de vista da carta do leitor.

Mas a questão ficaria certamente diferente se se mostrasse que a ocorrência de "negro" na expressão "período negro da história" é retomada de uma família parafrástica na qual se encontra também, por exemplo, a expressão "nuvens negras no horizonte", na medida em que esta expressão refere-se a determinadas condiçб̃es meteorológicas ou atmosféricas. Mesmo que esta expressão seja aplicada, por exemplo, ao clima político ou econômico de determinado país, imaginar que veicule racismo seria exagero. Como a cor escura das nuvens costuma efetivamente ser prenúncio de tempestades, a conotação racista negativa não se produz, já que tal discurso se funda em discursos anteriores sobre fatores climáticos e não em enunciados anteriores sobre raças e etnias. Uma outra associação possível (e histórica) é de negrume com noite, e de noite com obscuridade intelectual. Esta associação também leva a concluir que "período negro" pode não significar retomada de um discurso racista.

Na reportagem da revista que a carta critica, a palavra "negro" foi interpretada como se veiculasse sentido pejorativo. $O$ que isso significa? Pode significar que os leitores lêem o que querem, por exemplo. Ou que estamos diante do que Foucault chama de soberania do significante, isto é: se uma palavra ocorre, produzem-se todos os efeitos que ela pode produzir, se se suspendem as condiçб̃es de produção. Se se considera um fato como este relevante no sentido de que todos os efeitos que um elemento lingüístico produz devem igual- 
mente ser levados em conta (i. é, sem admitir a hipótese do erro de interpretação), então é possível que a razâo esteja pendendo para os que defendem a maior relevância do significante (p. ex., Lacan), a despeito das condições contextuais e históricas. Pode-se pedir ao leitor que distinga um dentre os diversos sentidos? Talvez não. Mas o fato de que, diante da palavra "negro", mesmo que ela pertença ao discurso da meteorologia, um leitor a leia como se ela fosse retirada, com seus efeitos, dos discursos racistas, indica fortemente que há condiçбes sociais para esta leitura. Significa, em outros termos, que o racismo estando vivo, a sensibilidade para tal leitura aumenta. A leitura do autor da carta pode estar equivocada. Mas é um sintoma. Neste sentido, um fato como este, ou melhor, este tipo de fato, coloca em xeque, por mais que seja relevante (e mereça minha simpatia, ainda) a tese clássica e ainda sólida (ou merecedora de defesa) da Análise do Discurso em relação ao sentido, que pode ser expressa pela seguinte citação de Pêcheux e Fuchs (1975:169):

Queremos dizer que, para nós, a produção do sentido é estritamente indissociável da relação de paráfrase entre seqüências tais que a familia parafrástica destas seqüiências constitui o que se poderia chamar a "matriz do sentido". Isto equivale a dizer que é a partir da relação no interior desta familia que se constitui o efeito de sentido, assim como a relação a um referente que implique esse efeito. Se nos acompanham, compreenderão, então, que a evidência da leitura subjetiva segundo a qual um texto é biunivocamente associado a seu sentido (com ambigüidades sintáticas e/ou semânticas) é uma ilusão constitutiva do efeito-sujeito em relação à linguagem e que contribui, neste domínio específico, para produzir o efeito de assujeitamento que mencionamos acima: na realidade, afirmamos que o "sentido" de uma seqüência só é materialmente concebivel na medida em que se concebe esta seqüência como pertencente a esta ou àquela formação discursiva (o que explica, de passagem, que ela possa ter vários sentidos)" (ênfase acrescida). 
Os autores introduzem, exatamente no lugar em que a citação termina, uma nota extremamente relevante para esta teoria que considera relevantes os fatores não estritamente lingüísticos para a própria constituição do lingüístico: "Acentuamos que esta concepção não se identifica com a das "leituras plurais" que sugerem a idéia de um pululamento infinito de significações, cada sujeito manifestando aí sua singularidade" (ibidem, p. 238). Vale dizer: para Pêcheux e Fuchs, a leitura do leitor de ISTOÉ não seria provavelmente defensável.

O movimento por um comportamento politicamente correto tem méritos políticos óbvios. Mas, em relação à linguagem, comete alguns equívocos relativamente banais. Por exemplo:

a) considera que a troca de palavras marcadas por palavras não marcadas ideologicamente pode produzir a diminuição dos preconceitos. Trata-se de uma tese simplista, já que é mais provavelmente a existência dos preconceitos que produz aqueles efeitos de sentido, embora não se possa desprezar o fato de que o discurso pode servir para realimentar as condições sociais que dão suporte às ideologias e aos próprios discursos. A hipótese das palavras "puras" é certamente ingênua;

b) em certos casos, adota um "etimologismo" insuportável, como quando considera que palavras como "history" se relacionam ao ponto de vista masculino, com base na identificação da primeira sílaba dessa palavra com a forma pronominal "his". O mesmo etimologismo que, como vimos acima, é certamente um equívoco também em relação à palavra "mulato", que seria politicamente incorreta, ofensiva, pelo fato de ser derivada de "mula"; é ainda o mesmo etimologismo que faz sugerir que determinados encontros não se chamem "seminários", pelo fato de esta palavra derivar de "semen" e conotar masculinidade, mas "ovulários", com as óbvias conotações femininas; no mínimo, esquece-se que "semen" não significa originalmente a semente masculina - na verdade, não se pode saber o que esta palavra significou originalmente. Mas pode-se pelo menos saber que a utilização desta palavra para referir a semente masculina é derivada de sua utilização para referir outras sementes... A lei de tal etimologismo 
(talvez de toda a etimologia) parece ser uma: recuemos até onde nos interessa;

c) freqüentemente, quando não há uma palavra sinônima que determinado movimento possa considerar politicamente correta (como é o caso de "homossexual" ou "homófilo", ao invés de "bicha", por exemplo), para evitar mesmo assim o uso de palavras marcadas, sugerem-se eufemismos de certa forma cômicos, ou verdadeiras definiçơes. Por exemplo, já que "adúltero" é uma palavra negativa, propõese a expressão "indivíduo casado com atividade sexual paralela". Já que "baixo" é uma palavra politicamente incorreta, propõe-se o uso da expressão "verticalmente prejudicado". Já que "prostituta"é uma palavra negativa, propõe-se "prestadora de serviços sexuais". Ora, essas são, a rigor, definições, mesmo que não sejam as mais objetivas. Se determinada sociedade condenar o adúltero ou desprezar os indivíduos de estatura pouco avantajada ou as prostitutas, tanto faz condená-los ou desprezá-los chamando-os de "adúltero" ou dizendo que têm atividade sexual paralela, chamando-os de "baixinhos" ou dizendo que se trata de indivíduos verticalmente prejudicados, chamando-as de "prostitutas" ou descrevendo a atividade que realizam. Afinal, são esses os fatos que provocam as atitudes de condenação. Se tais fatos continuarem sendo considerados negativos, em pouco tempo tais expressões veicularão exatamente os mesmos valores, os mesmos efeitos de sentido que veiculam hoje as formas condenadas.

Mais uma nota a respeito da questão da etimologia: a lingüística certamente já conseguiu demonstrar que a etimologia não é um bom método geral para nada. Mas, do ponto de vista do uso ideológico, ou retórico, da linguagem, vale a pena observar como a etimologia pode ser explorada para a justificação de determinados pontos de vistas. Portanto, trata-se de um sintoma de que o discurso sobre a origem das palavras ainda vigora, pelo menos confusamente, mantendo com ele a crença de uma linguagem com sentidos verdadeiros e puros. $O$ relevante não é, pois, a etimologia, mas o fato de que ela retorna eventualmente, em diversos discursos. 


\section{REFERÊNCIAS BIBLIOGRÁFICAS}

ANDERSON, P. (1983). A crise da crise do marrismo. São Paulo, Brasiliense. BAKHTIN-VOLOSHINOV. (1929). Marxismo e filosofia da linguagem. São Paulo, Hucitec.

BOURDIEU, P. (1983). Questőes de sociologia. Rio de Janeiro, Marco Zero. FERNANDES, M. (1988). Dírio da Nova República. vol 3. Porto Alegre, L\&PM. HUGHES, R. (1993). Cultura da reclamação. São Paulo, Companhia das Letras. KERBRACH-ORECCHIONI, C. (1977). La connotation. Presses Universitaires de Lyon.

PÊCHEUX, M. e FUCHS, C. (1975). "A propósito da análise automática do discurso: atualização e perspectivas". in: Gadet, F. e Hak, T. (org.). Por uma análise automática do discurso; uma introduçăo à obra de Michel Pêcheux. Campinas, Editora da Unicamp. pp. 163-252.

POSSENTI, S. (1994). "Sobre a linguagem politicamente correta". Comunicação apresentada no I Congresso Internacional da Abralin. Salvador, BA (a sair). RESENDE, O. L. (1992). "Palavras que ofendem". in:Folha de S. Paulo. 16.05.92. p. 2.

RIBEIRO, R. J. (1992). “Aqui não tem PC". in: Folha de S. Paulo; llustrada. 29.03. 92. p. 5-3. 